\title{
СЛОВООБРАЗОВАНИЕ КОЛЛОКВИАЛЬНЫХ НАРЕЧИЙ С КОМПОНЕНТОМ WEISE В СОВРЕМЕННОМ НЕМЕЦКОМ ЯЗЫКЕ
}

\section{WORD FORMATION OF COLLOQUIAL ADVERBS WITH THE WEISE COMPONENT IN MODERN GERMAN}

\section{A. Alekseeva E. Nikitina}

Summary: A productive way of forming adverbs is word production using semi-suffix weise. By the type of base of forming, there are three groups of adverbs with this component:

a) Adverbs with a substantive as the generating base;

b) Adverbs with the adjective name as the generating base;

c) Adverbs with a verb as the generating base.

Depending on the base the weise component can perform the function of a semi-suffix or a suffix.

Keywords: colloquial adverbs, word formation, semi-suffix, suffix, noun, adjective, semantic feature, generating base.
Алексеева Анна Борисовна

Старший преподаватель, Сибирский федеральный университет (2. Красноярск)

annblok@mail.ru

Никитина Елена Александровна

К.филол.н., доцент, Сибирский федеральный университет

(2. Красноярск)

injaz@inbox.ru

Аннотация: Наиболее продуктивным и частотным полусуффиксом коллоквиальных наречий является единица weise. В зависимости от производящей основы различают три группы коллоквиальных наречий:

а)наречия с существительным в качестве производящей основы; 6)наречия с прилагательным в качестве производящей основы; в)наречия с глаголом в качестве производящей основы.

В зависимости от основы компонент weise может выполнять функции полусуффикса или суффикса.

Ключевые слова: коллоквиальные наречия, словообразование, полусуффикс, суффикс, имя существительное, имя прилагательное, семантический признак, производящая основа.

К наречиям, производным от имён существительных, относятся следующие единицы: dutzend-, flider-, häufen-, kannen-, kleckschen-, liter-, reihen-, rudel-, scheffel-, scheibchen-, schock-, schritt- (schrittchen-), serien-, tropfen(tröpfchen-), zizerlweise. Производящие имена существительные могут быть представлены как словоформой единственного числа (ср.: schrittweise, dutzendweise), так и словоформой множественного числа (ср.: serienweise, reihenweise). Производящие имена существительные могут выступать в динумитивной форме: kleckschenweise, tröpfchenweise, schrittchenweise, scheibchenweise. Имена существительные, послужившие производящей основой наречиям на weise, можно разделить на следующие семантические группы:

1. Существительные, указывающие на единицы измерения длины, объёма: Tropfen, Schritt, Liter.

2. Существительные, указывающие на единицы исчисления: Dutzend, Schock.

3. Существительные, обозначающие совокупность людей, животных, вещей: Haufen, Reihe.

Общим семантическим признаком существительных всех семантических групп является партитативный признак. При соединении производящих существительных с компонентом weise последний проявляет свойства полуаффикса. Компонент weise сохраняет семантическую и формальную соотнесённость с этимологически исходным полнозначным словом Weise. Модифицирующее влияние компонента weise проявляется во внесении им 
в содержание производного наречия семы распределительности. Отсубстантивированные наречия на weise образуют две трансформы:

1. in + Substantiv.

2. Substantiv + für + Substantiv.

Cp.: schockweise (in + Schocken; Schock + für + Schock); schrittweise (in + Schritten; Schritt + für + Schritt).

В разговорной речи сема партитативности нейтрализуется, происходит актуализация квантитативного признака. Сема квантитативности служит для семантического переосмысления и создания нового семантического деривата, выраженного тем же существительным. Последнее, приобретя стилистическую маркированность, является производящей базой для соответствующего коллоквиального наречия. Схематически это можно изобразить так: нейтральное слово (существительное) - семантический коллоквиальный дериват (существительное) - словообразовательный коллоквиализм (наречие).

Словообразовательные наречия-коллоквиализмы с квантитативным значением распределяются на две группы: наречия с общим семантическим признаком «очень много, в большом количестве», и наречия с признаком «очень мало, в малом количестве». К первой группе относится большинство наречий, например: bergeweise, fuderweise. Адвербиальных единиц с семой «очень мало, в малом количестве» меньше. Данный словообразовательный ряд объединяет единицы; grammweise, tropfenweise (tröpfchenweise), schrittweise (schrittchenweise), scheibclienweise, zizerlweise.

При соединении с производяшими сушествительными компонент weise сохраняет связь с определяющим словом Weise, модифицирует содержание производного наречия и выражает принадлежность слова к грамматическому классу наречий. На основании этих трёх признаков компонент weise следует рассматривать, на наш взгляд, как полусуффикс.

Словообразовательный ряд наречий на weise с именем прилагательным в качестве производящей основы составляет 14 единиц. 6 прилагательных являются простыми производящими основами: blöder-, dummer-, netter-, schlauer-, törichter-, unsoliderweise. В качестве активных производящих основ выступают прилагательные с суффиксом -ig, -isch, -los. Cр.: drolliger-, fälschlicher-, idiotischer-, komischer-, sinniger-, ulkigerweise. В отличие от десубстантивных наречий соположение непосредственно составляющих в деадъективных единицах происходит при помощи соединительного асемантизированного элемента er.

Производящие основы исследуемых наречий представляют собой исключительно качественные прилага- тельные, которые можно разделить на две семантические группы:

1. Прилагательные, выражающие положительную оценку тому или иному факту, поступку человека: schlauerweise, netterweise.

2. Прилагательные, выражающие отрицательную оценку: idiotischerweise, fälschlicherweise.

Анализ фактического материала показал, что 13 имён прилагательных, послуживших производящей базой наречиям на -weise являются разговорноокрашенными. Наречие перенимает стилистическую маркированность от производящих прилагательных. Прилагательное komisch не обладает разговорной окрашенностью. В данном случае стилистическая маркированность появляется в результате словообразовательного акта, когда при взаимодействии двух нейтральных средств возникает коллоквиальное производное.

Адвербиальные единицы на weise подвергаются трансформе: es ist + производящая основа.

Cp.: sinnigerweise $=$ es ist sinnig

Наречия, чья оценка относится к личному подлежащему, могут образовывать трансформу с помощью предлога von:

blödsinnigerweise $=$ es ist blödsinnig von X (= Subjekt des Satzes).

Schlauerweise hat er davon nichts gesagt. [5]

Адвербиальные единицы с общим семантическим признаком «оценка поведения, умственного или психического состояния человека» могут иметь следующую трансформу: aus + Substantiv.

Cp.: netterweise = aus Nettigkeit; dummerweise $=$ aus Dummheit.

Трансформационный анализ показывает, что попытка трансформировать наречия на weise в синтаксические сочетания с определяемым существительным Weise даёт отрицательный результат. В большинстве наречий происходит изоляция компонента weise от существительного Weise. Основная функция данного компонента заключается в индикации адвербиальной категориальной принадлежности. Словообразовательный компонент weise показывает себя в формальном и семантическом плане избыточным, поскольку производящие словоформы способны самостоятельно употребляться в адвербиальной функции. К числу данных словоформ относятся отпартиципные образования: lesender-, spielenderweise и наречие fälschlicherweise.

Lesenderweise (= lesend) lerne ich die unregelmäßigen Verben.

В деадъективных наречиях компонент weise является 


\section{словообразовательным суффиксом.}

Таким образом, можно сделать вывод, что при присоединении к существительным компонент weise сохраняет связь с определяющим словом Weise, модифицирует содержание производного наречия и выражает при- надлежность слова к грамматическому классу наречий. Вследствие этого элемент weise рассматривается как полусуффикс. В деадъективных наречиях этот компонент является в формальном и семантическом плане избыточным и рассматривается в качестве словообразовательного суффикса.

\section{ЛИТЕРАТУРА}

1. Борисова Л.С. Словообразование наречий современного немецкого языка (на материале аффиксальных и сложных наречий): Автореф. дис. ... канд. филол. наук.- М., 1987.-18с.

2. Девкин В.Д. 0 двух новациях в немецком словообразовании.— - В кн.: Материалы научной сессии по итогам научно-исследовательской работы МПгу за 1992 г., т. Гуманитарные науки № 2.- М., 1991. С. 54-62

3. Степанова М.Д. Словообразование современного немецкого языка.— М.: Изд-во лит. на иностр. яз., 1953.—376с.

4. Степанова М.Д., Фляйшер В. Теоретические основы словообразования в немецком языке.— М.: Высш. шк., 1984. - 264c.

5. Словари и энциклопедии на Академике [Электронный ресурс]. URL: https://translate.academic.ru/ (дата обращения 10.05.2020).

6. Duden, C. Deutsches Universalwörterbuch //Hrsg. von der Dudenredaktion. - Berlin, 2015. - 2132S.

7. Duden Grammatik //Hrsg. von G. Drosdowski._Mannheim, Wien, Zürich, Bd. 4, 2016.—1344 S.

8. Fleischer W., Barz. I Wortbildung der deutschen Gegenwartprache.— Tübingen: Max Niemeyer Verl., 1992.—375S.

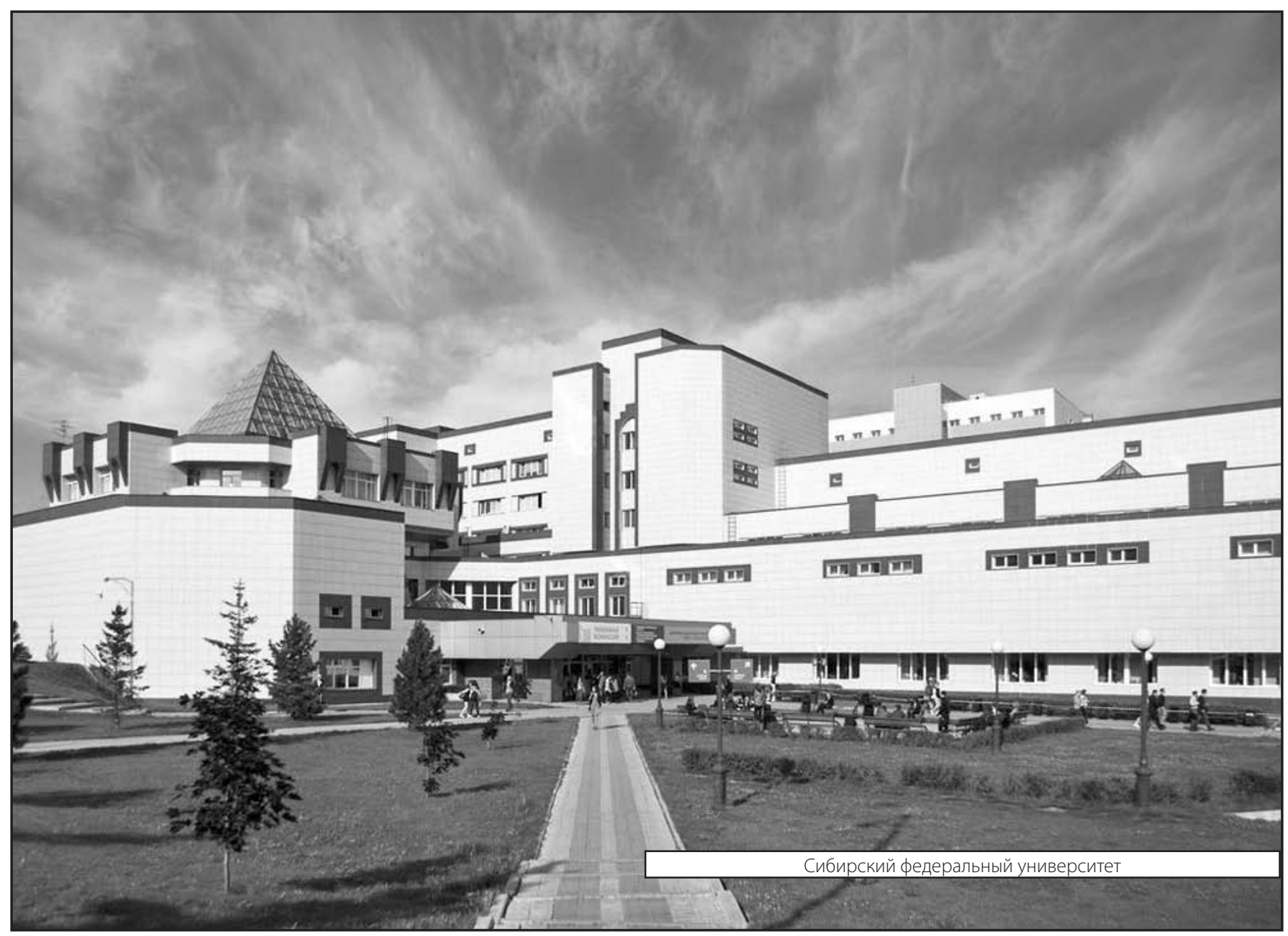

